\title{
La enseñanza a distancia de los SIG, en el marco de un modelo virtual participativo
}

José Miguel Santos Preciado

\section{Resumen:}

La progresiva implantación de las nuevas tecnologías de la comunicación, en el campo de la enseñanza, está modificando muchos de los planteamientos educativos tradicionales, hasta el punto de obligar al profesorado, como motor esencial del proceso pedagógico, a tener presente como afectan a la estrategia del aprendizaje las nuevas formas de comunicación y de elaboración de los materiales y recursos docentes. El modelo característico de la enseñanza presencial, basado en el contacto directo profesor-alumno, lleva camino de transformase en un nuevo modelo, apoyado por el entorno virtual formativo, aunque distante, más flexible y eficaz en algunos de sus presupuestos. Estos entornos virtuales ofrecen a la enseñanza unas posibilidades de comunicación, que afectan a la forma de transmitir el conocimiento y también a los recursos docentes y estrategias educativas correspondientes.

Estas nuevas circunstancias permiten plantearse la utilización de la metodología e-learning en la enseñanza de algunas materias específicas, como los "Sistemas de Información Geográfica", que, por sus peculiares características, se amoldan bien al empleo de un modelo educativo de esta naturaleza. En este sentido, se exponen, en el trabajo que presentamos, a partir de la experiencia directa del autor, una serie de sugerencias y recomendaciones para la elaboración de un curso virtual sobre SIG.

Palabras clave: Enseñanza on-line, Enseñanza e-learning, Educación virtual, Sistemas de Información Geográfica, Tecnologías de la Información y de la Comunicación.

\section{Abstract:}

The progressive introduction of the new communications technologies in the field of education is altering many of the traditional educational approaches, up to the point of forcing the teaching staff, as the essential driving force of the pedagogical process, to bear in mind how these affect the strategy of learning the new forms of communication, and the development of teaching materials and resources. The 
typical model of teaching by attendance, based in direct teacher-pupil contact, is on its way to being transformed into a new model, supported by the virtual formative en

vironment, although this is distant, more flexible, and efficient in some of its aspects. These virtual environments offer teaching some possibilities of communication that affect the form of transmitting knowledge, and also affect teaching resources and related educational strategies.

These new circumstances permit the use of the e-learning methodology in teaching certain specific matters, such as "Geographical Information Systems", which, due to their peculiar features, adapt well to the use of an educational model of this nature. In this sense, we set out a series of suggestions and recommendations for the preparation of a virtual course about G.I.S,. in the work that we present.

Key Words: On-line education, Virtual education, Geographical Information Systems, (G.I.S.) Information and Communications Technology.

José Miguel Santos Preciado. Departamento de Geografía. Universidad Nacional de Educación a Distancia (UNED). Madrid (España).jsantos@geo.uned.es 


\section{INTRODUCCIÓN}

La enseñanza de la Geografía, como la de cualquier otra materia de estudio, ha sufrido, recientemente, profundos cambios, como consecuencia de la incorporación de las nuevas Tecnologías de la Información y Comunicación (TIC) al proceso de aprendizaje. Este nuevo marco de referencia educativo ha afectado, sobremanera, a la enseñanza de los SIG, especialmente en el marco de la educación virtual. En este sentido, los fundamentos de la enseñanza virtual permiten un aprendizaje más individualizado, ajustado a las necesidades de cada persona, a la par que el tipo de recursos didácticos utilizados son capaces de desarrollar una transmisión de conocimientos y adiestramientos eficaces, flexibles y equilibrados, mejor adaptados a los requisitos del nuevo modelo en el que se debe desenvolver la docencia. Por ello, es la intención básica de este artículo mostrar como la metodología a distancia, implícita en la UNED, universidad donde vengo realizado mi labor docente, favorece una enseñanza que beneficia, particularmente, el proceso de enseñanza-aprendizaje de los SIG, materia de estudio que se aviene bien a experimentar las ventajas del modelo virtual.

\section{EL MODELO VIRTUAL FORMATIVO DE LA ENSEÑANZAA DISTANCIA}

La enseñanza virtual es algo que, hoy en día, está presente, de un modo u otro, en la mayoría de las universidades españolas. Un conjunto de conceptos han hecho fortuna en el panorama formativo: aula virtual, campus virtual, plataforma colaborativa, enseñanza on-line, sociedad en red, generación "net", etc., obedeciendo a las nuevas posibilidades que ofrecen las TIC en el campo de la enseñanza. El impacto de las redes de comunicación sobre la formación y la educación va a suponer, y en algunos contextos ya está significando, uno de los mayores cambios que haya tenido lugar en las instituciones educativas en las últimas décadas. Tanto es así, que algunos han llegado a comparar el momento que vivimos con la repercusión que tuvo la imprenta, en su momento, en la generalización del conocimiento, o la transcendencia del alfabeto en la transformación de una cultura oral a otra escrita (Cabero Almenara, 2000).

No cabe duda que el modelo tradicional ha acumulado un conjunto de deficiencias estructurales que habría que modificar, mediante el empleo de estrategias educativas diferentes, relacionadas con las nuevas tecnologías de la educación. Entre las ventajas más decisivas que la educación virtual aporta (Mengibar, 2000), 
podríamos destacar el proporcionar una mayor autonomía geográfica a las personas residentes en áreas alejadas de los centros educativos, que normalmente ven disminuidas sus posibilidades de acceso a la educación; el proveer de una mayor autonomía temporal, al no requerir de un horario fijo; el solucionar los problemas educativos en áreas de escasa demanda; el favorecer el acceso a las fuentes directas de información; la mejora de la comunicación entre profesores y alumnos por distintos medios; el perfeccionamiento de la gestión y administración de las instituciones; y, finalmente, el proporcionar una enseñanza más individualizada, que permite avanzar al alumno de acuerdo a sus peculiaridades personales y necesidades propias.

La realidad de la enseñanza virtual se apoya en las nuevas oportunidades organizativas y de comunicación que ofrecen las TIC, a la par que en la existencia de plataformas e instrumentos informáticos, capaces de favorecer la interrelación entre los miembros básicos del proceso de aprendizaje: profesor-alumno. Además, se debe destacar el papel más activo de ambos, tanto el desempeñado por el primero, en la preparación, diseño del proceso en su conjunto, y, finalmente, en el seguimiento o tutorización consecuente, como en la participación más dinámica y laboriosa del segundo.

\section{1. Las nuevas posibilidades organizativas y de comunicación, favorecidas desde el entorno on-line, en el campo de la educación}

La progresiva implantación de las nuevas tecnologías de la comunicación, en el campo de la enseñanza, está modificando muchos de los planteamientos educativos tradicionales, hasta el punto de obligar al profesorado, como motor esencial del proceso pedagógico, a tener presente como afectan a la estrategia del aprendizaje las nuevas formas de comunicación y de elaboración de los materiales y recursos docentes. El modelo característico de la enseñanza presencial, basado en el contacto directo profesor-alumno, lleva camino de transformase en un nuevo modelo, apoyado por el entorno virtual formativo, que, aunque distante, resulta más flexible y eficaz en algunos de sus presupuestos.

El entorno virtual ofrece, además, a la enseñanza unas posibilidades organizativas y de comunicación, que afectan, tanto a la planificación del proceso de aprendizaje y programación de la secuencia de actividades docentes, como a la forma de transmitir el conocimiento y también a los recursos docentes y estrategias educativas correspondientes. Entre los aspectos más notables a considerar debe- 
ríamos destacar los siguientes (Santos Preciado, 2006):

1. La multidireccionalidad en la transmisión del mensaje, lo que permite una interactividad e interconexión ilimitada entre los actores principales del proceso educativo (figura 1). Este hecho facilita, tanto una comunicación uno a uno, como uno a muchos y muchos a muchos. Estas nuevas posibilidades de comunicación pueden ser utilizadas por el profesor para desarrollar, tanto el aprendizaje individual autónomo (enseñanza asíncrona) como el aprendizaje cooperativo, tutelado o libre (enseñanza síncrona). Además, permite la existencia de un feed-back de información inmediato, de manera que el profesor conozca si el alumno responde al método y alcanza los objetivos fijados inicialmente.

Figura 1. La relación multidireccional del entorno virtual.

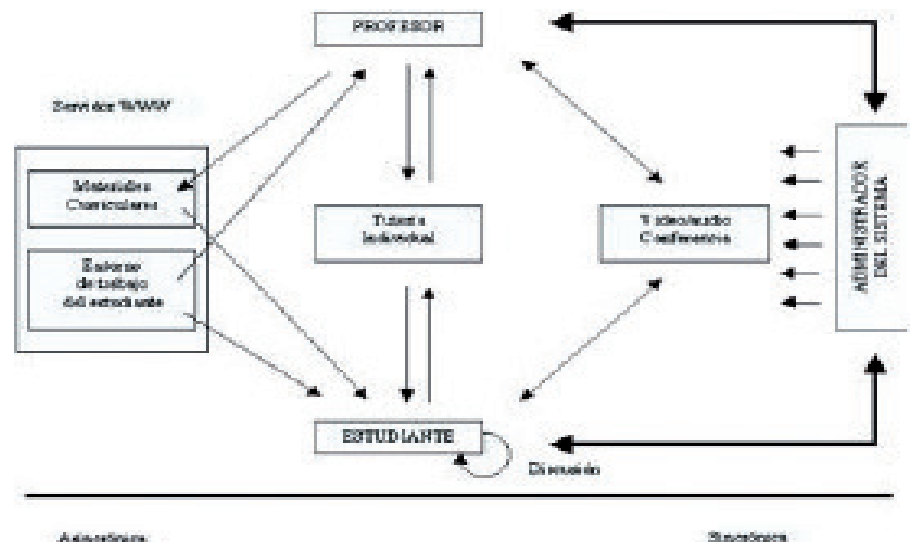

Fuente: Cabero Almenara, 2000.

2. La gran amplitud y variedad de la información disponible para los usuarios. La posibilidad de transmitir a distancia una gran cantidad de información en un tiempo record plantea la contingencia de disponer de nuevos recursos educativos en un nivel de escala desconocido hasta ahora. Esta información, transmisible en formato digital, ofrece la ventaja de la utilización de otros códigos diferentes al texto, que se amplía a los códigos sonoros, visuales y audiovisuales, en una estructura organizativa que abarca desde la secuencia lineal hasta la hipermedia. Ello supone la utilización de multiformatos, ya 
que la digitalización nos permite, no sólo transferir de forma más cómoda, fiable y fácil la información, sino también realizarlo en diferentes tipologías y formatos.

3. Sin embargo, la estrategia educativa del entorno virtual obliga a indagar en las nuevas posibilidades del medio en la estructuración y planificación del proceso de aprendizaje, la búsqueda de diseños específicos en los ma-teriales utilizados, la especificación de los roles a desempeñar por el profesor y los estudiantes y la determinación de nuevos criterios y estrategias de evaluación. El profesor se convierte en el mediador del modelo educativo, cuyos roles fundamentales son, por una parte, el de diseñador y productor de recursos adaptados a las necesidades de sus estudiantes y, por otra, el de tutor, por la que deberá realizar diferentes actividades que irán desde el asesoramiento a la motivación y a la redirección de la actividad realizada por el alumno.

4. Estas circunstancias modifican, sensiblemente, las tradicionales virtudes del profesor y el alumno, obligándoles a adquirir una serie de facultades y habilidades nuevas. Ello exige al profesor conocer la transformación de los documentos y recursos docentes clásicos a un formato utilizable en Internet, así como a estructurar los mismos en un discurso lógico, exportable por este medio (Marqués, 1999). Por su parte, los alumnos deben potenciar sus capacidades para el autoaprendizaje, mediante la elección adecuada de los medios y rutas de aprendizaje y la búsqueda significativa del conocimiento. En esencia, supone el alejamiento de la pasividad frente a la autoridad ilimitada del profesor y la búsqueda de soluciones personales, mediante un aprendizaje más activo y creativo.

\section{2. La formación virtual: el entramado instrumental, tecnológico, humano y cien- tífico}

El modelo educativo virtual debe tender a romper el modelo tradicional de la enseñanza, basado en la concepción educativa de que el conocimiento está depositado en una persona, "el profesor", mientras "el estudiante", como sujeto pasivo, debe esperar a que se lo transmitan. Pero, ¿cómo lograrlo?, ¿cómo adecuar las posibilidades que ofrecen las nuevas tecnologías a un proyecto que desarrolle un nuevo tipo de aprendizaje, que termine con determinadas lacras del sistema tradicional? Oliver y Reeves (1996) exponen la necesidad de que existan una serie de 
elementos básicos de cara a la construcción de ambientes de aprendizajes idóneos para la consecución de este objetivo: la creación de entornos colaborativos, la contextualización, la autonomía y la independencia del estudiante, la motivación, la interactividad, la utilización de metodologías activas y la adaptación del proceso educativo a las características de los receptores.

Para alcanzar una verdadera situación de aprendizaje colaborativo, en situaciones de teleenseñanza, es fundamental, en primer lugar, la utilización de un medio tecnológico adecuado (lo que se conoce como plataforma tecnológica on-line o virtual), que promueva un entorno visual y tecnológico participativo, que incorpore, tanto herramientas de comunicación sincrónicas como asincrónicas, herramientas de exposición de contenidos, módulos de evaluación, herramientas de seguimiento de la acción tutorial (estadísticas de participación de los alumnos, etc.), gestión de los trabajos colectivos o individuales, orientación y estrategia de aprendizaje, herramientas de navegación para la búsqueda y localización de información, etc. En fin, una herramienta educativa virtual que garantice el desarrollo de todo el proceso de comunicación multilateral, al que nos veníamos refiriendo, así como la disponibilidad de los recursos y estrategias educativas que el proceso de aprendizaje requiere.

Entre las posibilidades que ofrecen las plataformas más usuales empleadas con este fin podrían destacarse las siguientes:

- Separación precisa de las diferentes páginas de actividad: presentación de la asignatura, orientaciones didácticas detalladas por temas, contenidos (referencias bibliográficas, materiales audiovisuales, etc.), evaluación continua (clases prácticas, autoejercicios para resolver, etc.), herramientas de comunicación, trabajos en grupo, etc.

- Utilización de guías visuales que faciliten al estudiante la percepción del recorrido que debe seguir en su proceso de formación. Es conveniente, en este sentido, ofrecer al alumno un cierto margen de maniobra en la elección del recorrido de su aprendizaje. Desde este punto de vista, es importante la estructuración espacial y conceptual de los contenidos, que ordene los mismos en unidades didácticas organizadas de manera homogénea (introducción, desarrollo de contenidos, autoevaluación, actividades que refuercen el aprendizaje, elaboración de problemas, prácticas, comentarios de textos, proposición de ampliación de conocimientos, resumen de lo visto en el tema, propuesta de trabajo individual o 
de grupo, de discusión para el foro y guión de la sesión de chat del tema, etc.). En este sentido, el servicio de agenda favorece la planificación individualizada de cada materia de estudio o la planificación de actividades transversales (pruebas, evaluaciones, visitas, etc.) a la vista de las agendas de las asignaturas involucradas en dichas actividades.

- Las herramientas de comunicación deben ofrecer posibilidades interactivas lo más ricas y variadas posibles, reuniendo los servicios y funcionalidades más usuales de la comunicación telemática (correo electrónico, servicios de repositorio, foros, chats, videoconferencias, webconferencias, etc.), de manera que incorporen espacios virtuales para el debate, la discusión y la complementación.

- El sistema gestor de materiales educativos, que agilice las estrategias de aprendizaje, en orden a la comprensión de la materia de estudio, debe introducir, tanto módulos que sirvan para disponer información de interés, como aquellos otros destinados a la demostración razonada. Entre las múltiples herramientas y formatos podríamos destacar:

- La utilización del lenguaje oral y escrito en la representación de los contenidos, ayudándose de esquemas, gráficos y resúmenes, así como en los objetivos concretos fijados al comienzo de cada tema o unidad didáctica, etc.

- Ocupa un lugar relevante el glosario, diseminado a lo largo de cada uno de los temas de cada asignatura, que contribuye, de modo decisivo, a la comprensión correcta de cada uno de los términos o conceptos que aparezcan en el aprendizaje de la materia de estudio.

- A la transmisión de los contenidos contribuyen las películas de tipo "flash", dotadas de imágenes y animaciones con sonido sincronizado, diseñadas teniendo en cuenta los objetivos perseguidos en la transmisión de contenidos. Conviene resaltar la fuerza explicativa, demostrativa y didáctica de las mismas, al constituir una verdadera estrategia de acercamiento hacia el alumno.

- Finalmente, el sistema de control y evaluación del alumno, que debe servir para comprobar el grado de consecución de los objetivos planteados, así como de 
las competencias adquiridas. En este sentido, serán fundamentales:

- Los materiales de autoevaluación interactiva, que forman parte de un grupo específico de materiales docentes que pretenden, no solamente experimentar preguntas tipo, sino generar automáticamente pruebas de dificultad seleccionable.

- Las actividades prácticas, fundamentales en cierto tipo de asignaturas, ya que posibilitan verificar la adquisición de determinadas destrezas, que aproximan al estudiante a las prácticas que deberá desarrollar, una vez se incorpore al mercado laboral.

En el caso particular de nuestra universidad, la plataforma ALF, elaborada por el personal técnico informático de la misma, es una herramienta e-learning de publicación de material educativo y gestión de cursos en un entorno basado en la web. Sus principales funcionalidades permiten impartir y recibir formación, gestionar y compartir documentos, crear y participar en comunidades temáticas, así como realizar proyectos online. Aunque está desarrollada específicamente para la comunidad de profesores y alumnos de la UNED es también accesible al público en general.

La plataforma aLF consta de dos espacios básicos. El primero y más importante, es el Espacio General del Curso/Asignatura, preparado por el equipo docente, que incluye todos los contenidos, actividades, propuestas de evaluación del curso (figura 2), mediante una serie de iconos que conducen a funcionalidades específicas de la plataforma.

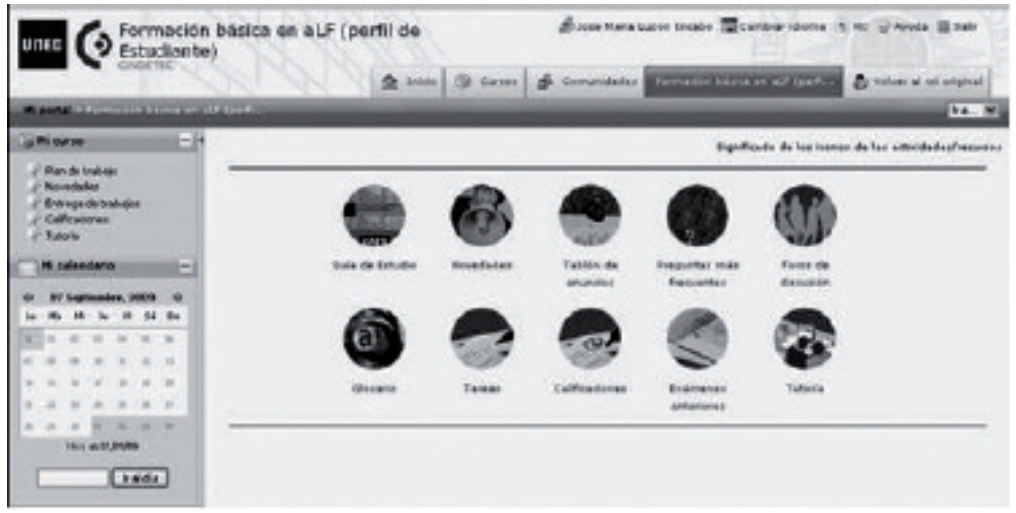

Figura 2. Principales funcionalidades de la plataforma ALF 
Las funciones de cada uno de estos iconos de navegación son: Guía de estudio, dedicada a acceder al documento donde se indica cómo está diseñada la asignatura (orientaciones didácticas, contenidos, material bibliográfico, criterios de evaluación, etc.); Novedades, que muestra los cambios que se han producido en el espacio virtual de la asignatura desde la última visita; Tablón de noticias, que conduce a un espacio expositor de noticias o avisos editados por el Equipo Docente; Preguntas más frecuentes, o lista de preguntas importantes con sus respectivas respuestas; Foros de discusión, herramientas para la comunicación escrita y en diferido en muchas plataformas; Glosario, agrupación de términos clave o importantes para una materia, disciplina o asignatura; Tareas, lista completa de tareas 0 actividades que ayudan a la evaluación continua de la asignatura; Calificaciones, herramienta de la plataforma encargada de gestionar las calificaciones; Exámenes anteriores, que permite el acceso a los modelos de examen de años anteriores; Tutoría, que posibilita acceder al grupo de tutoría, moderado por el profesor/a tutor/a personal.

En consecuencia, los roles más significativos que tendrán que desempeñar los profesores en estos nuevos entornos de formación se refieren, como hemos indicado anteriormente, al diseño de las estrategias de aprendizaje, a la elaboración de recursos educativos y a la tutorización. Ello implica la exigencia de destrezas, no sólo para la traslación de documentos a formatos utilizables en Internet, sino, también, y es lo verdaderamente importante, a la estructuración de los mensajes, utilizando los diferentes tipos de códigos disponibles a las necesidades de los estudiantes.

En cuanto a la tutoría, tenemos que señalar que se convierte en uno de los instrumentos de máxima significación, para conseguir que el sistema funcione con calidad y se favorezca un clima para el aprendizaje. En ella, la actividad del profesor resulta fundamental, lo que implica la realización de múltiples labores, desde el asesoramiento a la motivación y a la redirección de la actividad realizada por el estudiante.

En este sentido, tenderán a desvanecerse algunos roles clásicos desempeñados por el profesor, como el de mero transmisor de información, y potenciarse, sin embargo, otros, como el de evaluador y diseñador de situaciones mediadas de aprendizaje. Al mismo tiempo, deberá de poseer habilidades para trabajar y organizar proyectos en equipo, convirtiéndose en un organizador dinámico del currículum, 
estableciendo y adoptando criterios para la creación de un entorno colaborativo del aprendizaje.

\section{ADAPTACIÓN DEL MODELO VIRTUAL FORMATIVO AL PROCESO DE ENSEÑANZA-APRENDIZAJE DE LOS SIG}

\section{1. Algunas consideraciones para un diseño de la materia de estudio de los SIG en un entorno virtual}

Con vistas a obtener un adecuado aprendizaje de los SIG, de acuerdo a las competencias señaladas, ¿puede la enseñanza e-learning universitaria ser considerada mejor que la formación presencial? ¿Es la solución mixta una mejor solución que cada una de las dos opciones extremas? No cabe duda, que la utilización de la metodología on-line, en algunas asignaturas, puede ser interesante y motivadora. En el caso de la enseñanza de Sistemas de Información Geográfica, mi experiencia particular es que el entorno virtual contiene elementos fundamentales que favorecen el aprendizaje de esta materia específica de estudio, en la perspectiva de lograr un bagaje de conocimientos, habilidades y destrezas capaces de facilitar una incorporación más adecuada del alumno al mercado de trabajo.

Indudablemente, aprender a través de las TIC es más complicado que acudir a un aula. A priori, hay más obstáculos a tener en cuenta. Sin embargo, los fundamentos de la enseñanza virtual permiten un aprendizaje más individualizado, ajustado a las necesidades de cada persona, siempre que la organización y capacidad de respuesta del profesorado, coordinando y dirigiendo el proceso educativo, se ajuste a los requerimientos que exige este tipo de enseñanza, mediante un diseño adecuado del curso, adaptado a las necesidades de la materia de estudio. Veamos, en el caso de la enseñanza de los SIG, cual podría ser la respuesta organizativa y los medios necesarios para desarrollar una transmisión de conocimientos y adiestramientos eficaces, flexibles y equilibrados.

Una planificación general del proceso de aprendizaje de la asignatura requeriría la definición de un conjunto de elementos clave, relacionados con la programación de la actividad docente en un contexto temporal que posibilite una ordenada secuenciación de las tareas docentes a realizar por el alumno; elaboración previa de los recursos docentes; determinación de las estrategias de aprendizaje; concreción de las herramientas de comunicación entre los miembros que participan en 
dicho proceso: profesores del quipo docente-tutores-alumnos; y, finalmente, control del proceso de aprendizaje y evaluación de la asignatura. Veamos, cada uno de estos apartados de manera separada.

\section{Programación de la actividad docente}

La gran diferencia entre la presencialidad y la no presencialidad reside, precisamente, en que ésta última necesita de la explicitación de los procesos y de las metodologías de aprendizaje, más que la enseñanza presencial, y, por ello, las tareas a realizar deben estar siempre previamente diseñadas y ser conocidas, de antemano, por el estudiante. En el proceso de enseñanza-aprendizaje, el profesor debe elaborar el material de estudio, proponer los ejercicios 0 actividades prácticas que considere necesarios, definir las autoevaluaciones, los trabajos colectivos o individuales a realizar durante el curso, las herramientas de comunicación que considere más eficaces, y un largo etcétera de actividades de cuyo diseño y coordinación equilibrada depende el éxito o fracaso del curso virtual.

Así mismo, se debería determinar qué parte de la materia de estudio puede ser de autoaprendizaje y qué parte tutorizada, qué actividades pueden plantearse de forma sincrónica y cuales asincrónica. Además, definir, muy bien, qué papel debe desempeñar el tutor virtual en el seguimiento general del curso y en el particular de cada alumno, etc. En el caso de utilizar un entorno semipresencial (con reuniones presenciales de los profesores con los estudiantes), debería definir las actividades que realizarían en esas sesiones presenciales (exámenes, presentaciones, prácticas de laboratorio, clases de consolidación o ampliación de contenidos, etc.).

En general, el profesor ha de elaborar una guía o plan de la asignatura, de forma que el alumno, al empezar el curso, disponga, por escrito, de la programación de actividades temporalizadas de la asignatura, los materiales y recursos didácticos disponibles; en fin, las reglas del juego desde las que va a aprender y ser evaluado.

\section{Elaboración de recursos docentes de la asignatura y metodologías de aprendizaje}

En este tipo de estudios, es importante disponer de buen material de estudio: guías docentes, manuales, libros, material multimedia, programarios, etc. Tanto los encuentros presenciales, como el aprendizaje en el entorno virtual, han de servir para que el profesor oriente al estudiante en la adquisición de los conocimientos y 
habilidades.

En el caso concreto de la enseñanza de los SIG, se debería definir, a partir de la peculiaridad y rasgos distintivos de la materia de estudio, los resultados previstos en el aprendizaje u objetivos básicos a lograr, de forma que facilitemos el proceso de enseñanza de la asignatura.

Desde mi punto de vista, la secuencia de adquisición de conocimientos y destrezas debería ser, a grandes rasgos, la siguiente:

- Alcanzar un conjunto de nociones básicas sobre lo que son y para qué sirven los SIG.

- Conocer las peculiaridades de la información georreferenciada, su estructura cartográfica clásica y los modelos de organización espacial.

- Conocer el origen de la información y su acomodo a formato digital en los dos modelos de referenciación espacial (raster y vectorial).

- Conocer las funcionalidades básicas de los SIG raster y vectorial.

- Aprender el manejo de algún SIG comercial, que permita la comprensión práctica de este tipo de herramientas.

- Conocer los campos concretos de aplicación de los SIG en la resolución de variadas problemáticas medioambientales y territoriales.

Este simple esquema nos debe permitir valorar cómo definir los recursos didácticos, actividades docentes y estrategias de aprendizaje más interesantes para conseguir, en el entorno virtual, organizar el curso y alcanzar los objetivos y competencias propuestos. Los materiales y recursos docentes de mayor interés serían los que a continuación se detallan.

- Desde nuestro punto de vista, es muy importante disponer de un texto básico o Unidades Didácticas, escritas por el equipo docente, preparadas para el estudio independiente por parte del alumno. Dicho texto, que podría estar editado, bien en papel o mejor, incluso, en formato digital (utilizable en el curso virtual), servi- 
ría para que el alumno dispusiera de un material escrito de referencia básico. El texto se podría complementar con una guía didáctica detallada, disponible en el mismo tipo de formato, que expusiera, para cada tema o unidad didáctica, un conjunto de referencias de interés pedagógico (objetivos, contenidos previos a conocer, bibliografía complementaria, etc.).

- Otro tipo de información podría ofrecerse de forma complementaria a los alumnos. Entre las posibilidades que nos aportan los entornos virtuales de formación, nos encontramos, respecto al aprendizaje de los SIG, con una enorme y variada información suplementaria. Ahora bien, esta facilidad de transmisión de la información requiere de un esfuerzo de estructuración y organización, con vistas a una participación activa y constructiva del sujeto a quién va dirigida la enseñanza de la asignatura. Esta aptitud no queda constreñida, únicamente, al formato escrito, sino que afecta a materiales en formato audiovisual. Se nos ocurre un extenso conjunto de materiales didácticos complementarios, relacionados con varias de las competencias a adquirir por el alumno (conocimiento y manejo de la información geográfica georreferenciada, aplicación de los SIG a la resolución de problemas geográficos o de organización territorial, etc.) que podríamos poner a disposición del alumnado:

- Principales organismos origen de la información geográfica, tanto temática como espacial, en formato digital.

- Recopilación de textos o artículos de interés sobre los SIG, que complementen el contenido ofrecido en el manual básico, sobre diferentes aspectos, bien para ser analizados en alguna actividad complementaria, bien como forma de ampliar el campo de los contenidos disponibles.

- Repertorio de trabajos concretos de investigación que hayan utilizado el mismo software que emplee el alumnado en sus prácticas, donde, desde un esquema simple (exposición del problema a investigar, metodología y exposición de resultados), se muestren diversas posibilidades de aplicación de la tecnología SIG en la resolución de problemas territoriales y medioambientales.

- La existencia de recursos docentes, en formato multimedia, y su adecuación a la enseñanza de los SIG, permite plantearse el aprendizaje 
de partes de la asignatura, difíciles de aprender, de manera interactiva (figura 3), a partir de presentaciones que pueden disponer de componentes dinámicos incrustados a modo de "flashes". Este tipo de material es costoso de elaborar, por lo que la disponibilidad de un material ya confeccionado puede ayudar a la labor de la enseñanza de la asignatura. Muchos de estos elementos están construidos como modelos de simulación, que permiten responder a la pregunta de ¿qué pasaría si se realizara tal operación?

Figura 3. La herramienta GISWEB: un recurso multimedia interactivo al servicio de la enseñanza de los SIG.

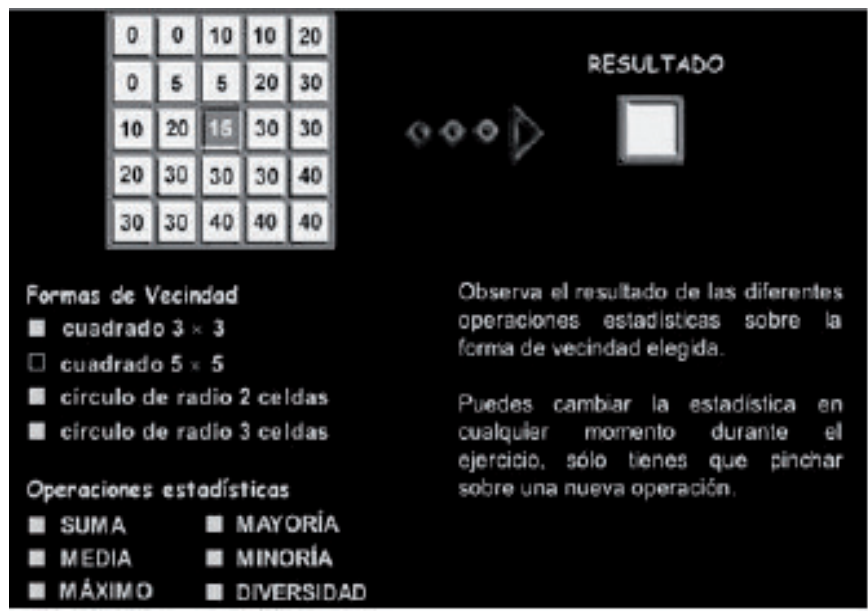

Fuente: GISWEB (disponible en la web del departamento de Geografía de la Universidad de Alcalá: http://www.geogra.uah.es/inicio/)

\section{La comunicación entre los distintos miembros participantes en el proceso de ense- ñanza-aprendizaje}

Una de las mayores potencialidades de la enseñanza virtual reside, precisamente, en la capacidad de relación interactiva que existe entre todos sus miembros. Un buen diseño del curso requiere que el profesor defina bien los espacios virtuales de relación y sus funcionalidades y objetivos.

El éxito del sistema de comunicación virtual reside en que el alumno ha de tener la sensación permanente de que hay alguien "detrás de la pantalla". En cada 
aula virtual, los alumnos inscritos escriben mensajes que contienen dudas o comentarios sobre la materia de estudio y el tutor escribe mensajes con sus respuestas. Cada alumno aprende de las contribuciones del tutor y del resto de los participantes, facilitándose de esta forma el aprendizaje colaborativo. Esta forma de trabajo es asíncrona, lo cual significa que no es necesario que estén todos los alumnos y tutores conectados al sistema al mismo tiempo; las respuestas a las preguntas se producen desplazadas en el tiempo. Para que el sistema funcione, la intervención del profesor ha de producirse con una periodicidad determinada y conocida por el alumno, como mínimo de dos o tres veces al día.

Además de este tipo de relación asíncrona, la UNED dispone de otro tipo de herramientas, síncronas, como las aulas AVIP, que permiten organizar a distancia, a modo de videoconferencia o webconferencia, una reunión programada entre alumnos y profesores, con la intención de resolver dudas, bien sobre la organización del curso o sobre aspectos relacionados con la temática concreta de la materia de estudio. En este sentido, la webconferencia es muy fácil de organizar y puede hacerse desde el domicilio de profesor y alumnos, pudiendo establecerse una relación alumno-profesor, con visualización en pantalla de la imagen del profesor (o alumnos autorizados), además de imágenes o esquemas empleadas en una pizarra electrónica (figura 4).

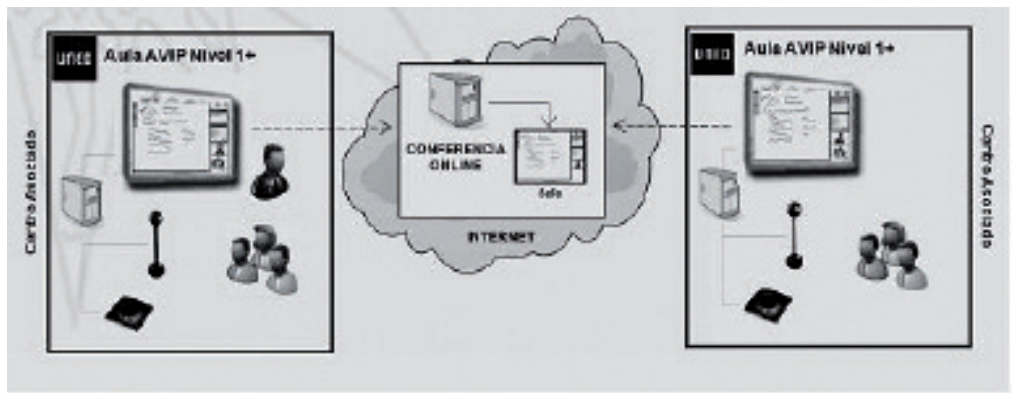

Figura 4. Relación interactiva profesor-alumnos a través de webconferencia

La utilización de la metodología virtual, frente a la metodología convencional, tiene las siguientes ventajas:

- Consultar dudas en el momento en que se producen, independientemente de la hora y lugar geográfico de conexión. 
- Contactar con otros compañeros de curso.

- Disminuir el aislamiento al que tradicionalmente se enfrentan los alumnos de educación a distancia.

- Enviar tareas y recibir correcciones de forma rápida.

- El foro constituye la herramienta de comunicación asíncrona más interesante. En el caso de la enseñanza de los SIG, podríamos plantearnos la creación de los siguientes foros:

- Un foro sobre aspectos generales de la asignatura, que diera respuesta a dudas sobre la organización de la misma (organización general del curso, criterios de evaluación, etc.).

- Un espacio virtual, preparado para contestar a cuestiones de carácter conceptual teórico.

- Diversos foros que respondieran, separadamente, a cada una de las actividades planteadas, bien de grupo o colectivas, bien individuales, siempre que éstas tuvieran una cierta entidad como para aconsejar su separación.

- Un espacio virtual de relación de los alumnos, que sirviera, de forma exclusiva, para comunicarse entre ellos.

- La reiteración de las preguntas, por parte de los alumnos, podría disminuirse si se preparara e incluyera la posibilidad de acceso a un conjunto de preguntas más frecuentes. Ello serviría de filtro a la participación de aquellos alumnos que intervienen en el medio de comunicación sin asegurarse de que la cuestión de interés que les lleva a realizar la consulta ha sido ya respondida.

- La preparación de un solucionario detallado de las actividades prácticas planteadas, incluso con imágenes resultado de operaciones intermedias, facilita la la rápida comunicación del profesor con el alumno, al enviar al foro de comunicación, en muy poco espacio de tiempo, la respuesta correcta a la duda planteada. 


\section{Control del proceso de aprendizaje y evaluación de la asignatura}

Entre las actividades de aprendizaje, debe tenerse presente la importancia de que el alumno participe en el proceso docente de forma activa. Por tanto, es imprescindible plantear al participante proyectos reales, basados en objetivos interesantes, apoyados en la tutoría socrática; en definitiva, en construir simulaciones donde puedan practicar aquellas tareas que les esperarán al día siguiente en su puesto de trabajo. Estas actividades son imprescindibles en el caso de la enseñanza de los SIG, pudiendo realizarse de manera individual o colectiva. Las mismas podrían consistir en:

- Pruebas o Actividades de Evaluación a Distancia que planteen la posibilidad de realizar ejercicios prácticos, a partir del software definido para el trabajo de la asignatura. Estos trabajos podrían ser realizados de forma individual o colectiva, constituyendo el tutor un elemento clave en el proceso de dirección y coordinación de los mismos. Los servicios en línea para el trabajo de grupo permiten al profesor y a los estudiantes compartir, tanto documentos como imágenes y otros materiales digitales de manera interactiva simultánea. De esta manera, podrían experimentar la dinámica práctica de grupo que les sería especialmente útil a lo largo de su carrera profesional.

- La posibilidad de ubicar, en la plataforma tecnológica, las imágenes o capas geográficas para trabajar en el SIG facilita la labor de distribución de las mismas y el trabajo práctico de los alumnos. Una variada información de este tipo, relativa a espacios geográficos diferenciados, permite plantearse actividades de autoevaluación simples, a modo de tutorial, en las que el alumno puede realizar operaciones, de complejidad creciente, previamente diseñadas por el equipo docente de la asignatura.

- La necesidad de disponer de un programa informático para la realización de la tarea del aprendizaje de la asignatura, fundamental en el caso de los SIG, puede verse favorecida por la conexión a la red. La posibilidad de descargar el programa por el alumno, a precio razonable, desde su domicilio, permite plantearse la posibilidad de un sistema mixto (trabajo en casa o en el aula informática del centro educativo), de acuerdo a las condiciones ofertadas por el distribuidor 
del sistema. En este sentido, la utilización de SIG libres, como gvSIG ${ }^{1}$, facilita enormemente la tarea propuesta.

- Prácticas de autoevaluación, más simples, bien estructuradas de acuerdo con las partes o temas de la materia de estudio, servirían para valorar el avance experimentado por cada alumno en la comprensión de la asignatura.

- Los trabajos prácticos se podrían complementar con la respuesta a preguntas o cuestiones de tipo más teórico, que servirían para comprender determinados aspectos de la asignatura, más centrados en el discernimiento del significado de conceptos o procedimientos de trabajo.

\section{2. Tutorización del alumnado}

La tutorización del alumnado, por parte de cada profesor responsable, constituye un elemento clave en el éxito del aprendizaje virtual. La necesidad de un seguimiento cercano, más si se desea respetar el modelo de la evaluación continua, exige que el índice de relación de alumnos por tutor no exceda mucho de la cifra de 50 personas. En caso de que así sea, se debería multiplicar el número de tutores de forma proporcional.

En la asignatura de SIG, los alumnos podrían disponer de dos opciones de ser evaluados: la evaluación continuada y la evaluación final. De esta manera, el estudiante sería evaluado, por una parte, mediante exámenes presenciales, mientras que por otra, a partir de las prácticas o trabajos individuales o en grupo elaborados previamente por el profesorado.

Para el seguimiento y la evaluación del curso en general y de los alumnos en particular, el profesor dispondría de los siguientes mecanismos:

- Las estadísticas que se extraen de la plataforma suministran el número de consultas realizadas por los estudiantes, las respuestas proporcionadas por los profesores correspondientes, el número de trabajos entregados mediante la misma, etc.

\footnotetext{
${ }^{1}$ gvSIG es un SIG libre, elaborado por los servicios informáticos de la Consejería de Infraestructuras y Transporte de la Comunidad Autónoma de Valencia (España), al que se puede acceder desde la página: http://www. gvsig.org.
} 
- Las encuestas de opinión, realizadas por los alumnos al final de cada curso, permitirían valorar la docencia, el sistema de evaluación y el material docente utilizado.

- Los materiales de autoevaluación interactiva forman parte de un grupo específico de materiales docentes que pretenden, no solamente experimentar preguntas tipo, sino generar automáticamente pruebas de dificultad seleccionable.

- Las Pruebas o Actividades de Evaluación que los alumnos envían al profesor, de acuerdo con un calendario establecido con antelación, servirían de referencia básica de evaluación del alumnado. Estarían compuestas por preguntas tipo test, preguntas de respuestas abiertas, trabajo prácticos realizados en grupos 0 individualmente a partir del software seleccionado como SIG, etc.

\section{A MODO DE REFLEXIÓN FINAL}

La implantación progresiva del modelo virtual de enseñanza ha permitido introducir nuevos planteamientos de docencia en áreas de conocimiento, como los Sistema de Información Geográfica (SIG), donde la enseñanza teórico-práctica es fundamental en su metodología de aprendizaje. En este marco educativo, la utilización de la enseñanza virtual en la línea de aplicación de los principios de la evaluación continua, favorece el aprendizaje de forma activa y autónoma.

\section{BIBLIOGRAFÍA}

- Badia, A.; Pallarés, M.; Llurdes, J.C. (2006). «L'ús de les noves tecnologies en l'ensenyament de la geografia dins l'EEES. Les assignatures de Geografia econòmica i social, Cartografia i fotointerpretació, i SIG». Digithum [article en línia]. Núm. 8. UOC. Disponible en: <http://www.uoc.edu/digithum/8/dt/cat/badia_pallares_llurdes.pdf>

- Burriel de Orueta, E. L. (2004a): "La base formativa común en la enseñanza universitaria de la Geografía en España", Boletín de la A.G.E., 38, págs. 47-70.

- Cabero Almenara, J. (2000). "La formación virtual: principios, bases y preocupaciones", en Pérez, R. (coords) (2000): Redes, multimedia y diseños virtuales, 
Oviedo, Departamento de Ciencias de la Educación de la Universidad de Oviedo, pp 83-102.

- Marqués, P. (1999): "Criterios para la clasificación y evaluación de espacios web de interés educativo", Educar, 25, pp 95-111.

- Mengibar Jiménez, J. (2000): “Apoyos telemáticos en la educación a distancia. ¿Son todo ventajas y facilidades?" en la Formación continua en la sociedad de la información. Centro virtual Cervantes. Disponible en la dirección de Internet http://cvc.cervantes.es/obref/formacion_virtual/formacion_continua/mengibar. $\mathrm{htm}$

- Nieto Masot, A. (2010): "El uso didáctico de los sistemas de información geográfica en el Espacio Europeo de Educación Superior", en Tejuelo. Didáctica de la Lengua y Literatura. Vol 9, n⿳01.

- Oliver, R. y Reeves, T. (1996): "Dimensions of effective interactive learning with telematics for distance education", ETR\&D, 44,4, pp 45-56.

- Santamaría Lancho, M. y Sánchez-Elvira, Paniagua, A. (2008): "La adaptación de la tutoría académica en la UNED al Espacio Europeo de Educación Superior". UNED. Red Estatal de Docencia Universitaria (REDU). Seminario Internacional: La Acción tutorial en la Universidad del siglo XXI.

- Santos Preciado, J. M. (1996): "Recursos informáticos y enseñanza de la Geografía”, en Didáctica Geográfica, Asociación de Geógrafos Españoles. Universidad de Burgos, pp 57-66.

- Santos Preciado, J. M. (2005): "Recursos docentes y enseñanza virtual. Aplicación al estudio de la Geografía y la Historia", en I Jornadas sobre el uso de las TIC en la UNED' 05.

- Santos Preciado, J. M. (2006): “Las Tecnologías de la Información y Comunicación y el modelo virtual formativo: nuevas posibilidades y retos en la enseñanza de los SIG", en Geofocus. Revista Internacional de Ciencia y Tecnología de la Información Geográfica, Madrid, pp 111-137. 